\title{
Outcome of Single Shot versus Serial Dilatation Technique for Percutaneous Nephrolithotomy
}

\author{
A.H.M Mostofa Kamal ${ }^{1}$, Md. Shawkat Alam ${ }^{2}$, Md. Naushad Alam ${ }^{3}$, Md. Safiul Alam Babul ${ }^{4}$, Anup Roy \\ Chowdhury $^{5}$, Shahriar Md. Kabir Hasan ${ }^{6}$, Md. Moynul Hoque Chowdhury ${ }^{7}$, Md. Habibur Rahman ${ }^{8}$
}

Received: 02 - 05 - 2020 Accepted: 03 - 08 - 2020 Conflicts of interest: None

Keywords: Percutaneous nephrolithotomy, single shot dilatation, serial dilatation.

\begin{abstract}
Background: Percutaneous nephrolithotomy (PCNL) is a common procedure for the removal of renal stones larger than $2 \mathrm{~cm}$ size with the advantages of lower morbidity rates, decrease in post-operative pain with faster post-operative recovery $\&$ thereby less duration of postoperative hospital stay. One of the fundamental steps of PCNL is the creation of the nephrostomy access. It can be done either by single shot dilatation or by multi-increment serial dilatation technique.
\end{abstract}

Objectives: To compare the outcome of PCNL done by single versus serial dilatation technique with specific reference to renal access time, total operative time, stone clearance rate, postoperative haematuria and duration of postoperative hospital stay.

Methods: It was a prospective interventional study with a sample size of sixty where odd number patients were included in group A (PCNL by single shot dilatation technique) $\mathcal{E}$ even number patients were in group B (PCNL by serial dilatation technique). After meticulous checking and rechecking, collected data were compiled and statistical analysis was done using computer based software SPSS (statistical package for social science, Version-16) and Students t-test and Chi-square test were applied for hypothesis testing. ' $P$ ' value $<0.05$ was considered as significant.

Results: Comparison between the two groups regarding stone size, stone clearance rate, postoperative haematuria and postoperative hospital stay were not statistically significant $(p>0.05)$. But mean renal access time in minutes (group A was $3.43 \pm 1.14$ and group $B$ was $4.20 \pm 1.37$ ) and the mean operative time in minutes (group A was $91.13 \pm 19.08$ and group B was $101.67 \pm 15.81)$ between the groups were statistically significant $(p<$ 0.05).

Conclusion: Percutaneous nephrostomy access can be successfully performed by single shot dilatation technique during PCNL with the advantages of shorter renal access time and total operative time.

1. Assistant Registrar, Transplant Surgery, National Institute of Kidney Diseases \& Urology (NIKDU), Dhaka

2. Associate Prof., Dept. of Urology, National Institute of Kidney Diseases \& Urology (NIKDU), Dhaka

3. Assistant Prof., Dept. of Urology, National Institute of Kidney Diseases \& Urology (NIKDU), Dhaka

4. Assistant Prof.,Dept. of Urology, National Institute of Kidney Diseases \& Urology (NIKDU), Dhaka

5. Assistant Registrar, Dept. of Urology, National Institute of Kidney Diseases \& Urology (NIKDU), Dhaka

6. Assistant Prof. Dept. of Urology, National Institute of Kidney Diseases \& Urology (NIKDU), Dhaka

7. Assistant Prof. Dept. of Urology, National Institute of Kidney Diseases \& Urology (NIKDU), Dhaka

8. Assistant Registrar, Urology, National Institute of Kidney Diseases \& Urology (NIKDU), Dhaka

Correspondence: Dr. A.H.M Mostofa Kamal, Assistant Registrar, Transplant Surgery, National Institute of Kidney Diseases \& Urology (NIKDU), Dhaka-1207, Bangladesh. E-mail: mostafarmc40@gmail.com 


\section{Introduction}

Renal stones represents a large portion in the field of urological practice and at present, Percutaneous nephrolithotomy (PCNL) is the gold standard procedure for treating renal stones larger than $2 \mathrm{~cm}$ size with the advantages of lower morbidity and faster post-operative recovery. The six basic stages of PCNL are: (1) Retrograde pyelography (RGP) with ureteric catheter insertion (2) renal access (3) tract dilatation (4) nephroscopy and stone fragmentation (5) ureteral double -J stent insertion and (6) nephrostomy tube placement. One of the fundamental steps of PCNL is the creation of the nephrostomy access. It can be done either by single shot dilatation or by multi-increment serial dilatation technique.

The use of multi-increment dilators is time-consuming and with each pass of the dilator cause injury to the collecting system (Davidoff et al., 1997). Also, there is a risk of significant bleeding when a sequential dilator is removed to allow placement of the larger one, because tract is left open, and there is no sheath in place to tamponade the bleeding. Travis and colleagues (1991) proved that single-increment dilatation was as safe as conventional techniques with minimal haemorrhage or parenchymal damage. Frattini and colleagues (2001) found a reduction in the fluoroscopy time and less haemorrhagic complications in singlestep than multi-incremental dilatation technique. In two others studies, Falahatkar et al. (2009) and Amjadi et al. (2008) found SSD and telescopic dilatation had a similar haematologic safety profiles.

\section{Materials and methods:}

This hospital based prospective interventional study with a sample size of sixty was conducted on admitted patients with renal stones with 2 to $4 \mathrm{~cm}$ size and underwent PCNL done either by single shot dilatation or by serial dilatation technique in the Department of Urology, NIKDU, Dhaka, from January 2016 to April, 2017 to compare the outcome of both techniques of tract dilatation in PCNL. Here odd number patients were included in group A (PCNL by single shot dilatation technique) \& even number patients were in group $\mathrm{B}$ (PCNL by serial dilatation technique). All patients were evaluated by detailed history, thorough physical examinations and relevant investigations. After proper counseling and informed written consent all patients were taken in operation theatre and under general anesthesia initially, on lithotomy position, a 5/6 F ureteric catheter placed transurethrally. Then on prone position, percutaneous access was created using an 18 $G$ access needle into the selected calyx under fluoroscopic guidance. A $0.035 \mathrm{Fr}$ straight-tipped guide wire was placed into the collecting system passed through the pelvis to the urinary bladder. Then nephrostomy tract was dilated either by single shot technique or by serial dilatation technique and a 24/ 26/28F Amplatz sheath positioned into the renal collecting system. Nephroscope was introduced and stone was disintegrated by using ultrasonic or pneumatic lithotripsy. Complete clearance of stone was confirmed fluoroscopically and endoscopically and then 5/6 Fr JJ stent was placed antegradely. On completing the procedure, the Amplatz sheath was removed after keeping a nephrostomy tube in situ. After meticulous checking and rechecking, collected data were compiled and statistical analysis was done using computer based software SPSS (statistical package for social science, Version-16) and Students t-test and Chi-square test were applied for hypothesis testing. ' $\mathrm{P}$ ' value $<0.05$ was considered as significant.

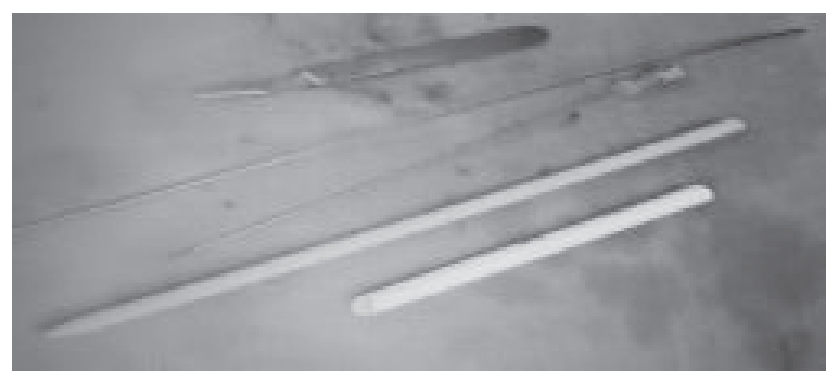

Fig.-1: One shot dilatation set.

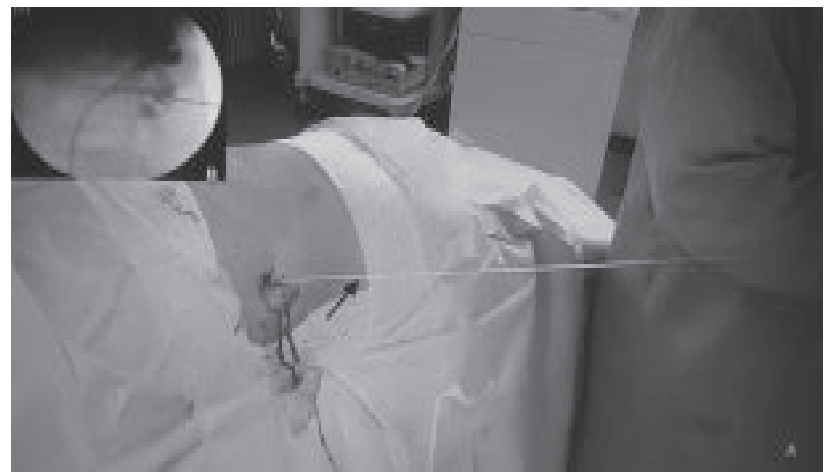

Fig.-2: The Alken guide (arrow) is placed under fluoroscopic guidance (B)

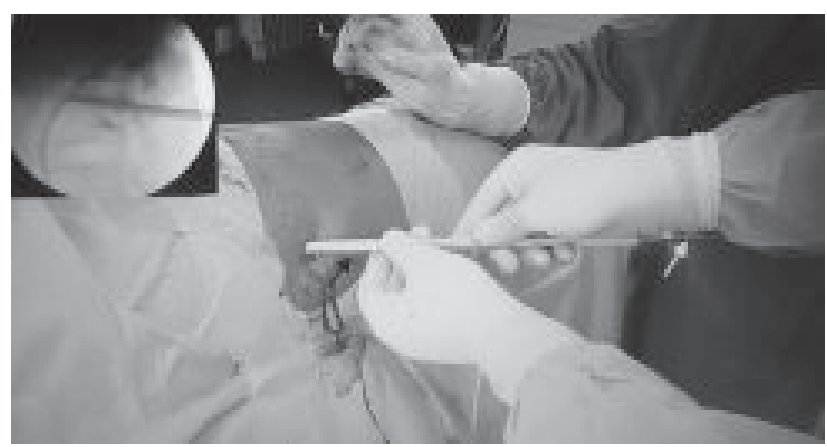

Fig.-3: The single 25F Fascial dilator (dark arrow) is pulled in on the Alken guide (white arrow) under fluoroscopic control. 


\section{Result:}

The age of the patients in both groups of the present study ranged between 18 and 63 years and the majority between 31-40 years, of which 13 and 11 patients belong to group A and group B respectively. Sex distribution was overall male 37 (61.67\%) and female 23 (38.33\%) with male female ratio $37: 23$. The mean stone size in group A was $2.86 \pm 0.57 \mathrm{~cm}$ and that was in group B $2.88 \pm 0.58 \mathrm{~cm}$ which was not statistically significant $(\mathrm{P}$ value $>0.05$ ). The mean time ( $\mathrm{min}$ ) of renal access in group A was $3.43 \pm 1.14$ and that in group B was $4.20 \pm 1.37$ which was statistically significant between the groups $(\mathrm{p}<0.05)$. In this study, mean $\pm \mathrm{SD}$ operative times was $91.13 \pm 19.08$ (55-135) $\mathrm{min}$ in group A and those was $101.67 \pm 15.81$ (70-135) min in group B. This difference was statistically significant (P value $<0.05$ ). Overall stone free rate/success rate was $93.3 \%$ (in 28 patients, complete clearance has occurred) in group A and success rate was $86.7 \%$ (in 26 patients, complete clearance has occurred) in group B. In this study, mean duration of haematuria in group A was $2.70 \pm 0.70$ days and in group B was $2.73 \pm 0.87$ days which was not statistically significant between the groups. The mean length of postoperative hospital stay in days was $3.40 \pm 0.86$ in group $\mathrm{A}$ and that was $3.40 \pm 0.72$ in group B. The length of hospital stay in both the groups was nearly same.

\section{Discussion}

Percutaneous nephrolithotomy (PCNL), is an accepted minimal invasive procedure for the removal of large renal stones more than $2 \mathrm{~cm}$ size and the dilatation of nephrostomy tract is a central step of PCNL which is usually performed by three dilatation methods: semirigid fascial dilators (Amplatz), metal telescopic dilators (Alken telescopic dilators: ATD) or nephrostomy balloon dilators (BD). Present study has been conducted to compare the outcome of PCNL done by single shot dilation and serial dilation technique. This study included 60 patients of renal stone 2 to 4 $\mathrm{cm}$ in size as per selection criteria.

In this study, mean age \pm SD of Group $A$ was $35.30 \pm 12.31$ (range 18- 62) and that of Group B was $37.83 \pm 12.40$ (range 19-63) years. The age range of present study is comparable with the study done by Harrech et al. (2014) in which mean age was 50.4 years. Kalpee et al. (2012) retrospectively compared PCNL done by Amplatz serial dilators (ASD) and by single step ballon(SSB) inflation device. The mean age in ASD was 55.9 years and in SSB was 48.8 years. Nour et al. (2014) had not similar age group in their study.

Sex distribution was overall male $37(61.67 \%)$ and female 23 (38.33\%) with male female ratio 37:23. Nour et al. (2014) showed 49 patients with overall male 33 and female 16 and male female ratio was 33:16.

The mean stone size in group A was $2.86 \pm 0.57 \mathrm{~cm}$ and that in group B was $2.88 \pm 0.58 \mathrm{~cm}$. which was not statistically significant $(\mathrm{P}$ value $>0.05$ ). Mean stone size of Harrech et al. (2014) was $3.8(1.6-11) \mathrm{cm}$. Nour et al.(2014) found that the mean stone size was $3.02 \mathrm{~cm}$ and $3.07 \mathrm{~cm}$ for Serial Alken dilator and single shot Amplatz dilator group respectively.

The mean time (min) of renal access in group A was $3.43 \pm 1.14$ and that in group B was $4.20 \pm 1.37$ which was statistically significant between the groups $(\mathrm{p}<0.05)$. Harrech et al.(2014) found the mean time of access 2.1 $\min (0.7-6.2)$. Ziaee et al.(2007) found that the mean access time in min was $5.93 \pm 4.94$ in without open stone surgery group and $6.24 \pm 3.63$ in with previous open stone surgery group respectively.

Mean \pm SD operative time was $91.13 \pm 19.08$ (55-135) min in group A and those was 101.67 \pm 15.81 (70-135) min in group $B$ which was statistically significant $(P$ value $<0.05)$. Harrech et al.(2014) found the mean operative time $54.8 \mathrm{~min}(25-137)$. Nour et al. (2014) found that the mean operative time was 110(90-210) min and 85 (60-160) min for Serial Alken dilator and single shot Amplatz dilator group respectively. Suelozgen et al. between January 2007 and February 2015, found mean operative time $102 \pm 266$ minutes (range 30270 minutes) and $134 \pm 44$ minutes (range 35 210 ) in one shot dilatation technique with and without previous history of open renal surgery respectively.

Overall stone free rate/success rate in this study was 93.3\% (in 28 patients, complete clearance has occurred) in group $A$ and that was $86.7 \%$ (in 26 patients, complete clearance has occurred) in group B. The success rate of stone clearance in studies conducted by Kalpee et al. (2012), Nour et al.(2014) and Harrech et al. (2014) were approximately similar.So, present study is similar to that of previous studies.

Postoperative haematuria occurred in group A patients up to 2 days in 13 (43.34\%) cases, 3 days in 13 cases $(43.34 \%)$ and 4 days in 4 cases $(13.33 \%)$ and that occurred in group B patients up to 2 days in $14(46.66 \%)$ cases, 3 days in 12 cases $(40.0 \%), 4$ days in 2 cases $(6.67 \%)$ and 5 days in 2 cases $(6.67 \%)$. So, mean 
duration of haematuria in group A was $2.70 \pm 0.70$ days and in group B was $2.73 \pm 0.87$ days which was not statistically significant among the groups.

Postoperative hospital stay in days was $3.40 \pm 0.86$ in group $A$ and that was $3.40 \pm 0.72$ in group $B$ which was statistically not significant. Studies conducted by Kalpee et al.(2012) and Nour et al.(2014) have found the similar result to this study in regards of duration of postoperative hospital stay.

Post PCNL residual stone present in 2 patients of group $A$ and in 4 patients of group $B$ which were cleared by ESWL except one patient in group $B$ in whome required Re-PCNL to clear the residual stone. Major operative complications like injury to adjacent organs, renal pelvis injury, violation of pleural space, excessive bleeding or infection did not occur in any patient underwent PCNL of both groups.

\section{Conclusion}

Results of present study indicates that time of renal access was shorter in single shot dilatation technique than serial dilatation technique for PCNL thereby leads to less radiation exposure in single shot technique. However, other variables were not statistically significant between the groups. So, single shot dilatation technique may offer a potential alternative to the serial dilatation technique for PCNL.

\section{References:}

1. Alken, P.,Hutschrenreiter, G., Gunther, R. et al.(1981).Percutaneous stone manipulation.J Urol, 125(4), pp. 463-7.

2. Amjadi, M.,Zolfaghari, A., Elahian, A. andTavoosi, A. (2008).Percutaneous nephrolithotomy in patients with previous open nephrolithotomy:One shot versus telescopic technique for tract dilatation. J Endourol, 22(3), pp. 423-5.

3. Baldwin, DD., Maynes,LJ., Desai, PJ., Jellison, FC., Tsai, CK. and Barker GR. (2006). A Novel Single Step Percutaneous Access Sheath: The Initial Human Experience.JUrol, 175, pp.1206-8.

4. Davidoff, R. and Bellman, GC.(1997). Influence of technique of percutaneous tract creation on incidence of renal hemorrhage. JUrol, 157(4), pp. 1229-31.

5. Fernstrom, I. and Johannson, B. (1976). Percutaneous pyelolithotomy.A new extraction
technique.Scand J UrolNephrol, 10(3), pp. 257-9.

6. Falahatkar, S., Neiroomand, H., Akbarpour, M.,Emadi,SA., Khaki, N.(2009). One shot versus metal telescopic dilation technique for tract creation in percutaneous nephrolithotomy: Comparision of safety and efficacy. J Endourol, 23(4), pp. 615-18.

7. Frattini, A.,Barbieri, A., Salsi, P. et al.(2001). One shot: A novel method to dilate the nephrostomy access for percutaneous lithotripsy. J Endourol,15(9), pp. 919-23.

8. Goel, A., Aron, M., Goel, R., Gupta, N P., Hemal, A K., Dogra, P N., Seth, A. (2003). Single step access into the pelvicalyceal system using the webb target dilator for PCNL and comparison with sequential dilatation technique. Indian J Urol, 20(1), pp. 14-7.

9. Goodwin,WE., Casey, WC.\& Woolf, W. (1955). Percutaneous trocar (needle) nephrostomy in hydronephrosis.J Am Med Assoc, 157(11), pp. 891-4.

10. Harrech, Y., Abakka, N., EI Anzaoui, J., Goundale, O. and Touiti, D. (2014).One-Shot Dilation in Modified SupinePosition for Percutaneous Nephrolithotomy:Experience From Over 300 Cases. Urology Journal, 11(3), pp. 1575-82.

11. Kalpee, A R., Venter, R. and Fourie, T. (2012).Single-centre comparison of a novel singlestep balloon inflation device and Amplatzsheath dilatation during percotaneousnephrolithotomy: A pilot study. S Afr J Surg, 50(3), pp. 79-81.

12. Lojanapiwat, B., Soonthornphan, S., Wudhikarn, S.(2001).Tubeless percutaneous nephrolithotomy in selected patients. J Endourol, 15, pp.711-3.

13. Margaret, S., Jodi, A. and Yair, L. (2016) $1 / 2$ Urinary Lithiasis: Etiology, Epidemiology, and Pathogenesis $1 / 4$ (ed 11 ${ }^{\text {th }}$ ) Campbell-Walsh Urology, Philadelphia, Elsevier, pp.1170-1199

14. Marguet,CG.,Springhart, WP., Tan, YH., Patel, A., Undre, S., Abala, DM.et al. (2005).Simultaneous combined use of flexible ureteroscopy and percutaneous nephrolithotomy to reduce the number of access tracts in the management of complex renal calculi.BJUInt,96, pp. 1097-100.

15. Matlaga, B.\& Assimos, DG.(2002).Changing indications of open stone surgery.Urology.59, pp. 490-3. 
16. Nour, HH., Kamal, AM.,Zayed, AS., Refaat, H.,Badawy, MH. and El-Leithy, TR. (2014). Singlestep renal dilatation in percutaneous nephrolithotomy: A prospective randomised study. Arab Journal of Urology, 12(3), pp. 219-222.

17. Safak, M., Gogus, C., Soygur, T. (2003). Nephrostomy tract dilation using a ballon dilator in percutaneous renal surgery: Experience with 95 cases and the comparison with the fascial dilator system.UrolInt, 71(4), pp. 382-4.

18. Suelozgen, T., Isoglu, C., Turk, H., Yoldas, M., Karabicak, M., Ergani, B., Boyacioglu, H., Ilbey, Y. and Zorlu, F. (2016).Percutaneous nephrolithotomy with one-shot dilation method: Is it safe in patients who had open surgery before?.Can UrolAssoc J, 10(3-4), pp. E132-E135.

19. Turney, BW., Reynard, JM., Noble, JG.\& Keoghane, SR.(2012). 'Trends in urological stone disease'.BJU Int, 109 (7), pp. 1082-7.
20. Travis,DG., Tan,HL.and Webb, DR. (1991). Singleincrement dilatation for percutaneous renal surgery: an experimental study. Br J Urol, 68(2), pp. 144-147.

21. Wezel, F., Mamoulakis, C., Rioja, J., Michel, MS., de la Rosette, J., Alken, P.( 2009). Two Contemporary Series of Percutaneous Tract Dilation for Percutaneous Nephrolithotomy. J Endourol, 23(10), pp.1655-61.

22. Wickham, JE. andKellett, MJ.(1981). Percutaneous nephrolithotomy. Br Med J,283, pp. 1571-2.

23. Yuhico, MP.\&Ko, R.(2008).'The current status of percutaneous nephrolithotomy in the management of kidney stones'. MinervaUrolNefrol, 60(3), pp. 159-75.

24. Ziaee,SA., Karami, H., Aminsharifi, A.,Mehrabi, S., Javaherforooshzadeh, A. ( 2007). One-Stage Tract Dilation for Percutaneous Nephrolithotomy: Is It Justified? J Endourol, 21(12), pp. 1415-20. 